\title{
Three-dimensional ultrasound of the female pelvic floor and 3D-power doppler angiography to assess endopelvic vascularization in pregnancy and puerperium
}

\author{
Juan Troyano-Luque*1, Mercedes Febles Borges ${ }^{2}$, Ana Isabel Padilla-Pérez ${ }^{1}$, Salvatore Andrea Mastrolia ${ }^{1,3}$, José Luis \\ Trujillo-Carrillo ${ }^{1}$, Luis San Frutos ${ }^{4}$, Tirso Pérez-Medina ${ }^{4}$ \\ ${ }^{1}$ Department of Obstertrics and Gynecology, Hospital Universitario de Canarias, Tenerife, Spain \\ ${ }^{2}$ Department of Obstetrics and Gynecology, Hospital de Manacor, Mallorca, Spain \\ ${ }^{3}$ Department of Obstetrics and Gynecology, Azienda Ospedaliero-Universitaria Policlinico di Bari, School of Medicine, \\ University of Bari "Aldo Moro", Bari, Italy \\ ${ }^{4}$ Department of Obstetrics and Gynecology, Hospital Universitario Puerta de Hierro, Madrid, Spain
}

Received: July 21, 2015

DOI: $10.5430 / j b g c . v 5 n 2 p 23$
Accepted: August 30, $2015 \quad$ Online Published: September 7, 2015

URL: http://dx.doi.org/10.5430/jbgc.v5n2p23

\begin{abstract}
Introduction and hypothesis: We studied ten different three-dimensional ultrasound (3D-US) and three-dimensional PowerDoppler angiography (3D-PDA) variables to assess female pelvic floor status and endopelvic vascularization. We hypothesize that $3 \mathrm{D}-\mathrm{US}$ is a reliable method to determine and evaluate changes occurring in the pelvic floor during normal pregnancy and puerperium, and can be used by any urogynecology specialist with US-imaging experience. We aimed to validate this method for clinical application.

Materials and methods: We performed a prospective study of 162 nulliparous pregnant women evaluated at weeks 12,28 and 36, and at 48 hours postpartum and three months post-delivery. At each of the five visits, we performed transperineal 3D-US of the pelvic floor and 3D-PDA to assess periurethral vascularization.

Results: Quantification of the vaginal anterior vaginal wall anchors (AWA) is an anthropometric parameter sensitive to changes in pregnancy and puerperium. Significant differences in AWA were observed according to delivery mode, being lower in vaginal deliveries than cesarean sections and even lower in prolonged labor deliveries and those in which episiotomy was performed. Posterior uretrovesical angle (UVA) increased during pregnancy, partially recovering after delivery although less so in those with epidural analgesia. Urethral sphincter volume (USV) decreased significantly during labor and postpartum. Periurethral vascularization increased during pregnancy and decreased significantly after delivery. Levator hiatus area (LHA) increased during pregnancy and decreased after delivery. Patients who received epidural analgesia and oxytocin showed better LHA recovery. Prolonged labor and greater fetal head circumference increased LHA. The anorectal angle (ARA) increased during pregnancy and decreased postpartum.

Conclusion: All 3D-US variables and their changes during pregnancy, childbirth and the postpartum period are measurable using the Virtual Computer-Aided Analysis (VOCAL method) with automatic threshold, which is more reliable and faster for measuring USV. AWA as an important new biometric parameter should be included in the study of the pelvic floor.
\end{abstract}

Key Words: Three-dimensional ultrasound, Pelvic floor, Prospective study, Virtual Computer-Aided Analysis, Anterior wall anchors

*Correspondence: Juan Troyano-Luque; Email: jtroyanol@sego.es; Address: Department of Obstetrics and Gynecology, University Hospital of Canary Islands, Ctra. Ofra, s/n, 38320, San Cristóbal de La Laguna, Santa Cruz de Tenerife, Spain. 


\section{Introduction}

The major causes of female pelvic floor disorders are pregnancy and childbirth, and women with at least one delivery develop pelvic floor disorders more often than nulliparous women. ${ }^{[1,2]}$ Levator ani muscle lesion is responsible for many pelvic floor disorders, and the prevalence of symptomatic lesions of this muscle after vaginal delivery ranges from $15 \%$ to $35 \% .{ }^{[3]}$ Similarly, increased levator hiatus during pregnancy and after delivery reflects distension of the levator ani. ${ }^{[4,5]}$

Multiparity, advanced maternal age, prolonged labor and fetal macrosomia are related with lesions of the elevator ani and anal sphincter. ${ }^{[6,7]}$ The use of forceps is also associated with increased pubo-vesical muscle lesions and increases the incidence of anal sphincter tears. ${ }^{[7,8]}$

All these factors have been studied using three-dimensional ultrasound (3D-US) and by 3D-power Doppler angiography (3D-PDA) to determine the extent of such lesions arising during pregnancy and the subsequent physiological implications. 3D-US is currently considered an important diagnostic tool in the assessment of the pelvic floor.

The objectives of our study were to determine changes during normal pregnancy and puerperium in:

(1) Three pelvic floor compartments (anterior, central and posterior) during normal pregnancy and puerperium using 3D-US imaging.

(2) Periurethral vascularization during the different phases of the study using 3D-PDA imaging.

(3) Maximum height of vaginal anterior wall anchors (AWA) as a new biometric measure.

\section{Materials and methods}

We conducted a prospective, multicenter study involving the departments of Obstetrics and Gynecology, Hospital de Manacor (Mallorca Island) and Hospital Universitario de Canarias in Tenerife (Canary Islands) between April 2012 and August 2013. The study was approved by the institutional committee following World Medical Association Declaration of Helsinki regarding ethical conduct of research in both institutions. Inclusion and exclusion criteria for patients are shown in Table 1.

Of 174 women initially recruited, 12 were excluded: one elective abortion for Edwards syndrome and eleven failed to attend the outpatient clinic after delivery or missed more than one visit before. The final study sample comprised 162 women.

\section{Study protocol}

Each patient was evaluated on five occasions; three times during pregnancy and twice after delivery, according to the following schedule: 1st visit before weeks 12 of gestation; 2nd visit at 28 weeks; 3 rd visit to 36 weeks; 4 th visit at 48 hours postpartum; and 5th visit at three months postpartum.

Table 1: Criteria for study inclusion and exclusion

\begin{tabular}{l}
\hline Inclusion criteria \\
\hline Caucasian, primiparous or miscarriage before 12 weeks of \\
pregnancy. \\
Singleton pregnancy. \\
Less than 12 weeks pregnancy at first visit: gestational age (GA) \\
estimated by ultrasound: CRL $\leq 52 \mathrm{~mm}$. \\
Informed consent to participate in the study. \\
Exclusion criteria \\
Present or past urinary or fecal incontinence. \\
History of pelvic surgery: hemorrhoids, anal fistulas, vaginal or \\
uterine surgery, anexectomy, myomectomy, etc. \\
History of any kind of muscular or neurologic disease that could \\
cause weakness or paralysis of pelvic floor musculature. \\
Regular consumption of any medication or drugs that could affect \\
pelvic floor vascularization or musculature.
\end{tabular}

At each of the five visits, the participants underwent 3D-US imaging of the pelvic floor and completed an internationally accepted questionnaire based on the International Consultation Questionaire-Urinary Incontinence Short Form (ICIQUI-SF).$^{[9]}$

The ultrasound examinations were performed using a Voluson 730 Expert 3D multi-vaginal probe (3-9 MHz), GE Medical System (Kretztechnik GMBH, Zipf, Austria).

Volume capture was performed by the same two observers physicians (A and B) in each hospital, with over 20 years of professional experience each and previously demonstrated inter and intra-observer reproducibility.

Patients were scanned in the gynecologic lithotomy position with a bladder volume between $175 \mathrm{ml}$ and $200 \mathrm{ml}$, calculated by 3D-US volumetry. The scans were performed by transperineal route but with a transvaginal probe for ease and versatility of use, inserting the probe in the introitus.

For the acquisition of sagittal plane images, the probe was directed towards the abdominal wall at an angle of $30^{\circ}$ with respect to the longitudinal axis of the pregnant.

After visualizing the three compartments of the pelvic floor in the same plane, the first volume was captured with the patient in repose (see Figure 1A). Then, without moving the probe, we selected the 3D-PDA option and captured a 3D image of the periurethral vasculature (see Figure 1B), with the following settings: Power (PWR): 100\%; Gain: 7.4; Frequency: medium; Quality: High; Wall Filter: Low 1; Pulse repetition frequency (PRF): $0.6 \mathrm{kHz}$.

Subsequently, to obtain the volume with the Valsalva maneuver, the image was captured at the point of maximum effort by the patient while maintaining the same sagittal plane. 
Finally, to selectively study the posterior compartment, the probe was oriented perpendicular to the vaginal axis.

Four volumes of the pelvic floor were captured; three in the sagittal plane of reference for the analysis of the anterior and central compartment as follows: one at rest, one with the Valsalva maneuver and a third evaluation of the pelvic floor (at rest) with 3D-PDA. The fourth volume was obtained in the coronal plane for the study of the posterior compartment.

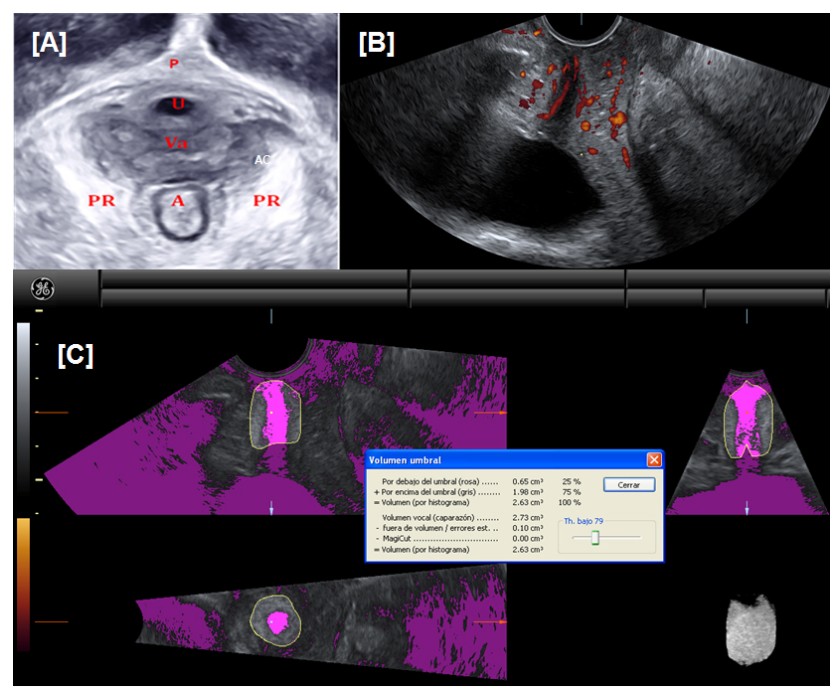

Figure 1: (A) Three-dimensional ultrasound imaging of the urogenital hiatus. U: Urethra; P: Pubis; Va: Vagina; A: Anus; PR: Pubo-rectal muscle. (B) The power Doppler (PD) option was selected to capture three-dimensional images of the para-urethral anatomotic vascular complex and the Santorini plexus. (C) Urethral sphincter volume captured using VOCAL Threshold Mode

In all cases we chose to use the VOCAL technique with automatic threshold mode (TVM) to assess urethral sphincter volume and 3D-PDA vascularization indices (vascularization index (VI), flow index (FI) and vascularization flow index (VFI), since this measurement mode is observer independent and is less time-consuming than the manual VOCAL mode (MVM) as well as being more accurate (see Figure 1C).

The variables studied for each patient are shown in Table 2.

Each observer (A and B) measured the 10 parameters twice within a period of 24 hours. Regarding vaginal AWA as a biometric parameter in our study, assessment of the anchors was performed in the levator hiatus, measuring the maximum distance between the anchors and the lower edge of the urethral sphincter in the axial plane (see Figure 2). In this regard, the TUI modality (Tomographic Ultrasound Imaging) has proved an optimal method for measurement, allowing a $4 \times 4$ format with 15 slices $1.5 \mathrm{~mm}$ apart (see Figure 3 ).

Regarding statistical analysis, a descriptive analysis of the Published by Sciedu Press variables was performed by calculating the mean and $95 \%$ confidence intervals, or medians and quartiles 1 and 3 depending on distribution. For comparisons, we used Student's $t$ test or the Mann-Whitney $U$ test and ANOVA or Kruskal-Wallis test, as appropriate. Spearman correlation coefficients were used to study the correlation between variables, and multivariate analysis was also performed using multiple regression. All analyses were carried out with SPSS 17.0 (SPSS Inc. Chicago, USA).

Table 2: Ultrasound variables studied in each patient at each of their 5 visits

\begin{tabular}{ll}
\hline Abbreviation & Extensive form \\
\hline UVA & Urethral-Vesicle Angle \\
USV & Urethral Sphincter Volume \\
MVM & Manual VOCAL Mode \\
TVM & Threshold VOCAL Mode \\
VI & Vascularization Index \\
FI & Flow Index \\
VFI & Vascularization Flow Index \\
LHA & Levator Hiatus Area \\
AWA & (Maximum height of vaginal) Anterior Wall Anchors \\
ARA & Anorectal Angle \\
\hline
\end{tabular}

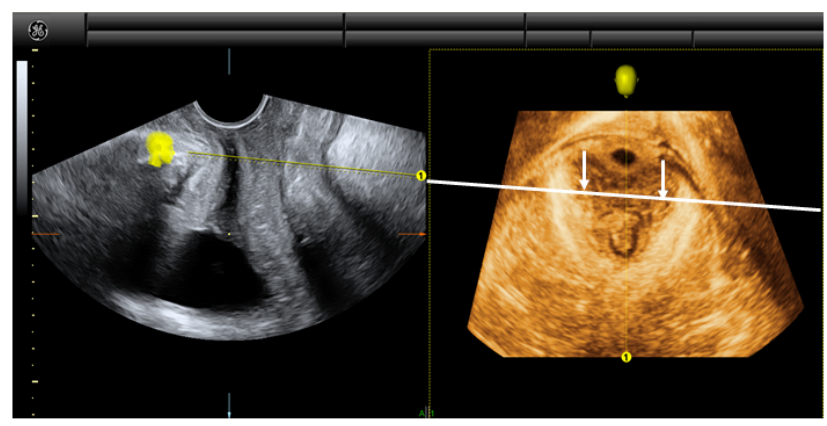

Figure 2: Measurements of vaginal anterior wall anchors maximum height: distance between the anchors and the lower edge of the urethra (arrows)

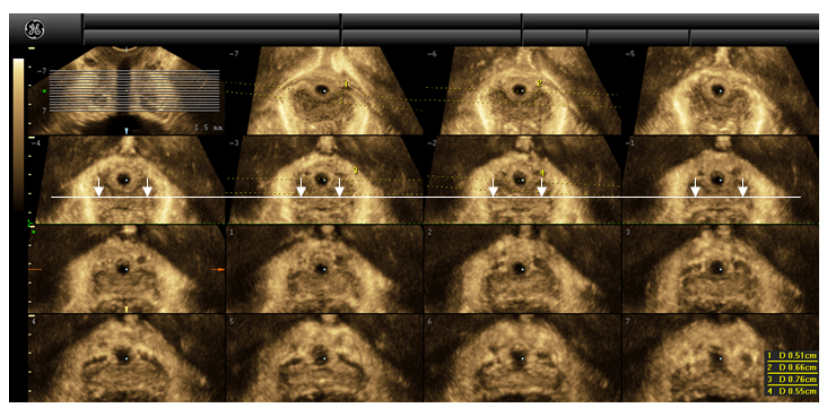

Figure 3: Maximum height of vaginal anterior wall anchors measured using TUI: Tomographic Ultrasound Imaging 


\section{Results}

\subsection{Maternal variables}

The mean age of the participants was 27 years $\left(\mathrm{P}_{25-75}\right.$ 24-31). Regarding body mass index (BMI), most began pregnancy with a healthy weight with mean BMI of 24.02 $\left(\mathrm{P}_{25-75} 21.61\right.$ to 27.03$)$. BMI increased to the end of pregnancy; at the third visit, median BMI was $28.86\left(\mathrm{P}_{25-75}\right.$ 26.50 to 31.81 ). At three months postpartum, most participants were slightly overweight, with a mean BMI of 25.45 $\left(\mathrm{P}_{25-75} 22.03\right.$ to 28.57$)$.

\subsection{Symptoms: clinical questionnaire}

The results of the questionnaire are shown in Table 3. We disregarded the questionnaire conducted at 48 hours after delivery since the results were practically the same as those obtained at the third visit and the patients were not yet able to appreciate and evaluate the changes in symptoms in just 48 hours.

Urine loss (with urge and stress component) was reported by increasing numbers of patients throughout pregnancy (32\%), but the number of women reporting this symptom decreased (5\%) at three months after delivery.

Urinary frequency was undoubtedly the most common complaint reported $(59.7 \%)$. More than half had already reported this at their first visit and this proportion increased throughout pregnancy, reaching $80.6 \%$ of the patients in the third trimester. Three months after delivery, $32.2 \%$ still had urinary frequency.

Table 3: Results of the questionnaire on clinical symptoms

\begin{tabular}{|c|c|c|c|c|}
\hline (ICIQ-UI-SF) & 1st VISIT & 2nd VISIT & 3rd VISIT & 5th VISIT \\
\hline MEAN LIQUIDS (litres) & 2 & 1.9 & 1.8 & 1.7 \\
\hline STRESS URINARY INCONTINENCE (nº cases) & 4 & 50 & 50 & 8 \\
\hline URGE URINARY INCONTINENCE URGENCY (nº cases) & 10 & 21 & 18 & 16 \\
\hline PROTECTOR (nº cases) & 3 & 23 & 29 & 8 \\
\hline POLYAQUIURIA ( ${ }^{\circ}$ cases) & 97 & 117 & 131 & 52 \\
\hline NOCTURIA ( $n^{\circ}$ cases) & 76 & 89 & 107 & 21 \\
\hline ENURESIS ( $n^{\circ}$ cases) & 0 & 0 & 0 & 0 \\
\hline CONSTIPATION ( ${ }^{\circ}$ cases) & 13 & 23 & 18 & 5 \\
\hline FLATUS INCONTINENCE (nº cases) & 0 & 0 & 0 & 3 \\
\hline FECAL INCONTINENCE (nº cases) & 0 & 0 & 0 & 0 \\
\hline
\end{tabular}

Note. (ICIQ-UI-SF): International Consultation on Incontinence Questionnaire-Urinary Incontinence-Short Form.

Nocturia was another of the symptoms reported by most patients. The number of cases increased during pregnancy, reaching $66.1 \%$ at the third visit. After delivery, this greatly decreased to only $12.9 \%$. No patient had nocturnal enuresis during pregnancy or after delivery.

Regarding other symptoms, a small number of patients reported constipation during pregnancy, which decreased after delivery. No patient had fecal incontinence before or after birth, and only one referred flatus incontinence at three months postpartum.

\subsection{Labor and delivery variables}

Labor started spontaneously in $75.8 \%$ and was induced in $19.4 \%$. Oxytocin was administered in $75.8 \%$ of cases. Epidural analgesia was administered in $85.5 \%$. Mean time in labor was 6.23 hours (95\% CI 5.34 to 7.11). Mean expulsive time for patients who delivered vaginally was 1.16 hours (95\% CI 0.9-1.41).

\subsection{Type of delivery}

Of a total 162 deliveries, $75.8 \%$ were vaginal, of which $16.1 \%$ were instrumental deliveries and $24.2 \%$ were cae- sarean. In the instrumental deliveries, $60 \%$ were by vacuum extraction and $40 \%$ by forceps. Episiotomy was performed in $53.2 \%$ of the vaginal deliveries. Almost half the patients (46.8\%) had no tears, $25.5 \%$ had first-degree and $27.7 \%$ had second degree tears. No third degree tears were recorded.

\subsection{Neonatal variables}

Median birthweight was 3,350 $\mathrm{g}\left(\mathrm{P}_{25-75} 2940-3640\right)$ and the median head circumference was $34.5 \mathrm{~cm}\left(\mathrm{P}_{25-75} 33.50\right.$ to 35.00$)$.

\subsubsection{Anterior compartment ultrasound results}

We analyzed 1,200 volumes, making a total of 2,700 measurements of the variables in each patient at each of their five visits.

\section{(1) Posterior uretrovescical angle (UVA) expressed in de- grees $\left(^{\circ}\right)$}

Mean UVA values clearly increased throughout pregnancy and at 48 hours of delivery, by $12^{\circ}$ from the first visit $(\bar{X}$ : $114.0^{\circ} ; 95 \%$ CI $\left.111.5-116.4\right)$ to the fourth visit $\left(\bar{X}: 125.8^{\circ}\right.$; 95\% CI 122.9-128.6) $(p<.01)$, as shown in Figure 4. 


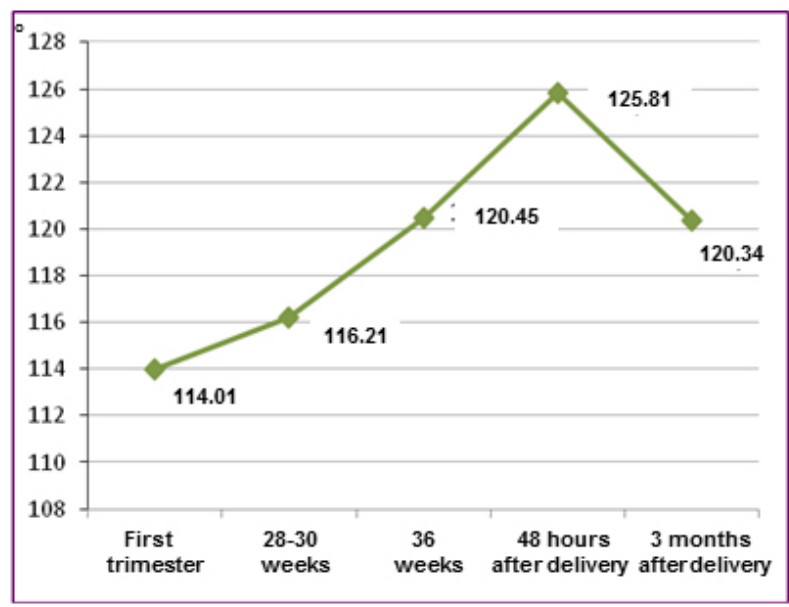

Figure 4: Urethrovesical angle (mean values in degrees)

At two months postpartum, mean UVA was $\bar{X}: 120.3^{\circ} ; 95 \%$ CI 117.7-122.9 thus showing a decrease of $5^{\circ}$ with respect to the immediate postpartum period $(p<.01)$, but not declining to the baseline value recorded in early pregnancy. The difference in mean UVA between the first and last visit was $6.3^{\circ}(p<.01)$.

We, therefore, conclude that UVA increases throughout pregnancy and then decreases somewhat after birth but does not return to baseline values recorded in the first trimester of pregnancy.

\section{(2) Urethral sphincter volume in $\mathbf{c m}^{3}$}

We observed a clear trend towards loss of urethral sphincter volume throughout pregnancy and even after birth (see Figure 5).

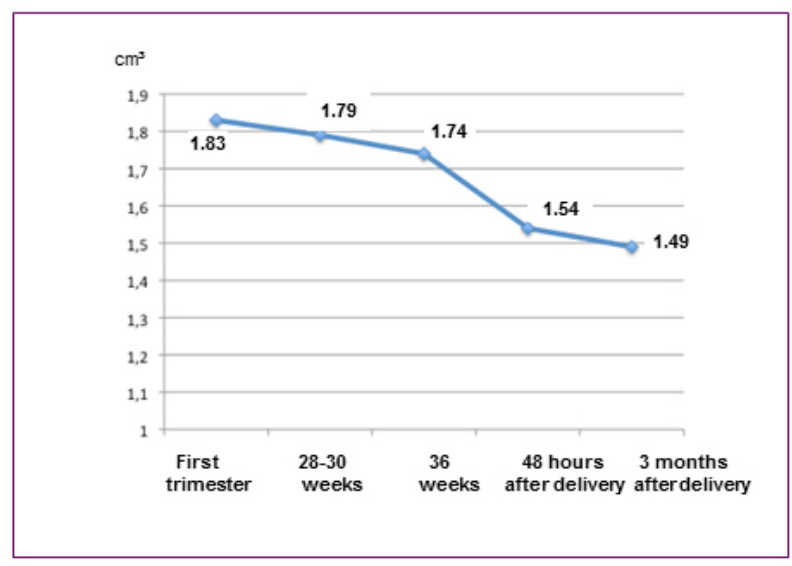

Figure 5: Urethral sphincter (mean values in $\mathrm{cm}^{3}$ )

Although urethral sphincter volume losses were subtle during pregnancy, they became more evident after birth. At three months of delivery, the mean loss was 0.3 cc compared

Published by Sciedu Press to baseline values at the first visit $(p<.01)$. Therefore, there is a loss of urethral sphincter volume following pregnancy and delivery.

The mean value of vascularization index (VI) expressed as a percentage $(\%)$ increased significantly during pregnancy and decreased significantly after delivery $(p<.01)$, as shown in Figure 6.

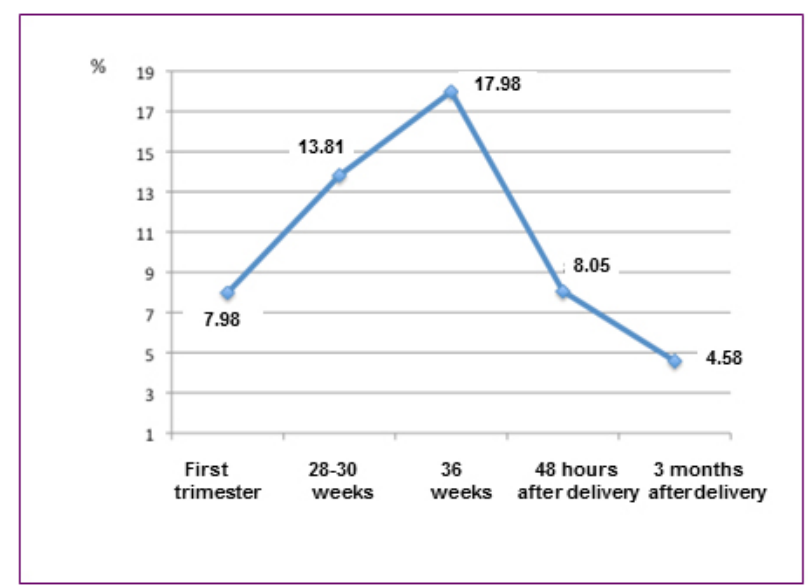

Figure 6: Vascularization Index (VI) (mean values)

Mean value of the flow index (FI), measured on a scale of $1-100$, also increased throughout pregnancy and decreased after delivery $(p<.002)$ as shown in Figure 7, although the changes were less pronounced than those of VI.

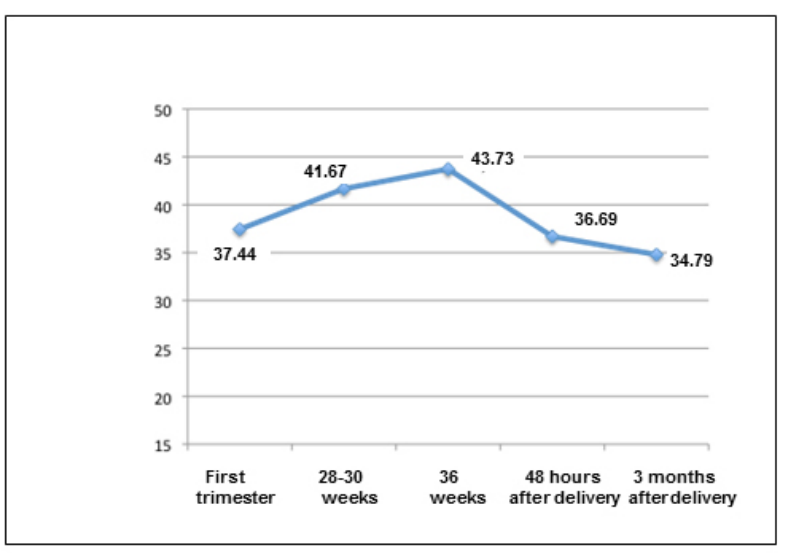

Figure 7: Flow Index (FI) (mean values)

Similarly, mean value of the vascularization flow index (VFI), measured on a scale of 1 to 100 , also increased during pregnancy and then fell sharply after delivery; at 3 months postpartum, this was almost half of the value recorded at the first visit (see Figure 8). 


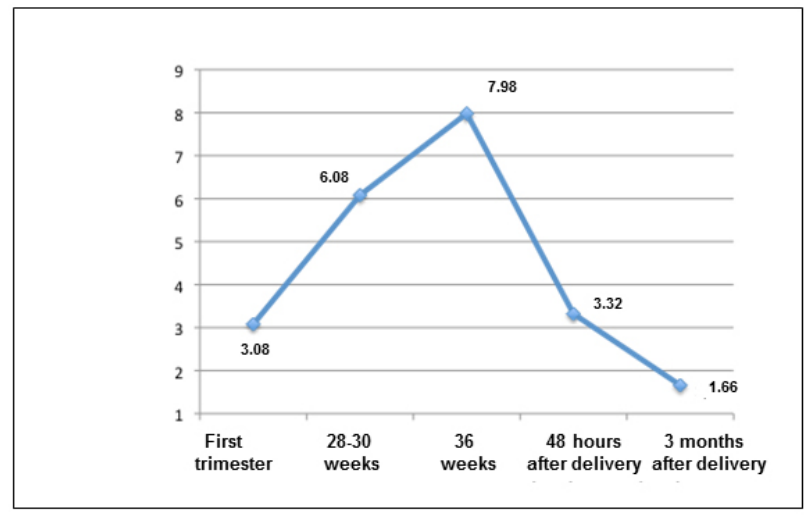

Figure 8: Vacularization-Flow Index (mean values)

\subsubsection{Central or medium compartment ultrasound re- sults}

(1) Levator Hiatus Area (LHA) in repose, measured in cm $^{2}$

Figure 9 shows how LHA, in blue, increased during pregnancy and reached its maximum at 48 hours of delivery. We recorded a mean increase of $1.6 \mathrm{~cm}^{3}$ between the first visit and 48 hours postpartum $(p<.01)$.

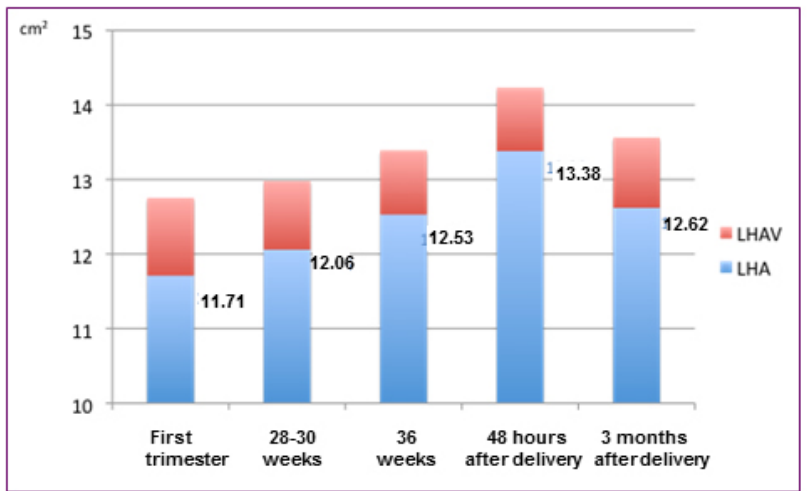

Figure 9: Length of urogenital hiatus area in repose (LHA) shown in blue, and length of urogenital hiatus area with Valsalva Maneuver (LHAV) shown in red (mean values in $\mathrm{cm}^{2}$ )

At the last visit, three months after delivery, mean LHA had decreased with respect to 48 hours postpartum value ( $p<$ .01 ) but did not descend to the baseline value recorded in early pregnancy. Our data indicate that LHA increases by $0.9 \mathrm{~cm}^{2}$ after the first birth $(p<.01)$.

\section{(2) Levator hiatus area with Valsalva maneuver (LHAV), measured in $\mathbf{~ c m}^{2}$}

By measuring the LHAV, we were able to calculate the distension of the urogenital hiatus, i.e. the difference between the area measured on Valsalva and the area measured in repose, shown in red in Figure 9.
The mean values of LHAV were always greater than those measured in repose over the five visits, with a mean increase of $0.9 \mathrm{~cm}^{2}$ (range 0.8 to 1.0 ).

(3) Maximum height of vaginal anterior wall anchors (AWA), in cm

Mean AWA values recorded at each visit are shown in Figure 10. This figure shows how the maximum height of AWA, measured in $\mathrm{cm}$, decreased progressively throughout pregnancy and after delivery. This loss of AWA means that the " $\mathrm{H}$ " form of the vagina in nulliparous patients changed to a " $\sqcap$ " form.

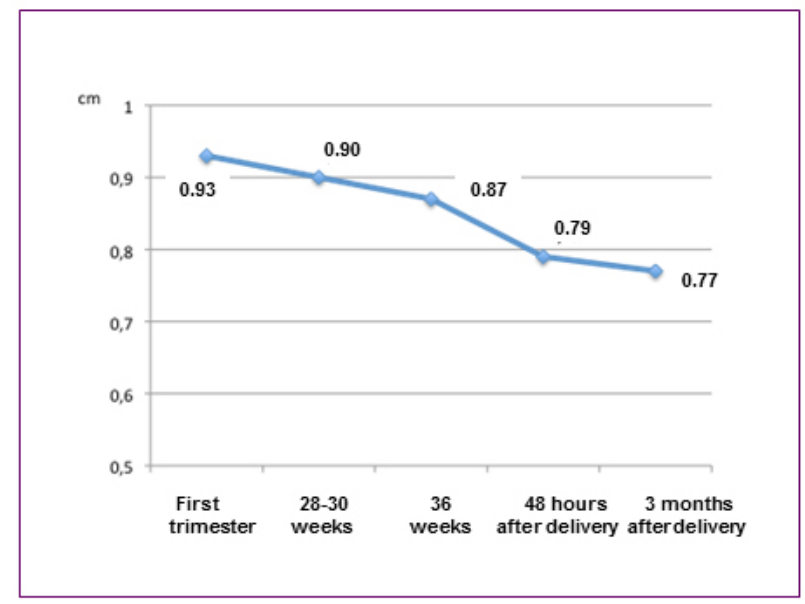

Figure 10: Vaginal Anterior Wall Anchors (AWA) (mean values in $\mathrm{cm}$ )

The loss of AWA height measured at three months of delivery was $\bar{X}: 0.7 \mathrm{~cm}, 95 \%$ CI $0.7-0.8$, with respect to the first visit $(\bar{X}: 0.9 \mathrm{~cm}, 95 \%$ CI $0.9-0.9)(p<.01)$.

Mean AWA height decrease was related to the mode of delivery, with lower AWA in women with instrumented deliveries than spontaneous deliveries and highest AWA in women with cesarean deliveries. Likewise, AWAs were significantly lower in patients undergoing episiotomy, and the longer the expulsion period, the lower the maximum height of the anchors.

\subsubsection{Posterior compartment ultrasound results}

The anorectal angle (ARA) in degrees $\left({ }^{\circ}\right.$ ) followed a similar pattern of evolution to that of the posterior UVA evolution. ARA clearly increased throughout pregnancy and immediately after birth, and at three months postpartum showed a tendency to return to first trimester values (see Figure 11).

We observed an increase of $9^{\circ}$ between the fourth visit $(\bar{X}$ : $140.6 ; 95 \%$ CI $138.9-142.4)$ and the first ( $\bar{X}: 131.5 ; 95 \%$ CI 129.6-133.4), and a decrease of $2.5^{\circ}$ between the fifth visit $(\bar{X}: 138.1 ; 95 \%$ CI 136.3-139.9) and the fourth (both differences with $p<.01)$. Therefore, all the patients showed a mean increase in ARA of $6.5^{\circ}$ after the first birth $(p<.01)$. 


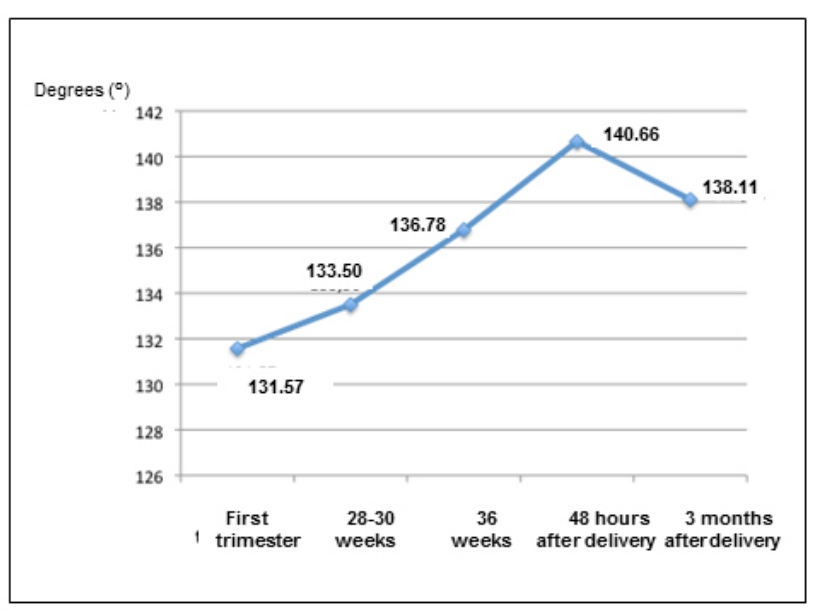

Figure 11: Ano-rectal angle (ARA) (mean values in degrees)

\section{Discussion}

\subsection{On the method}

In the present study, we used the transperineal route with a three-dimensional vaginal probe. Although many different routes have been used (urethral, vaginal, rectal transperineal) for pelvic floor examination, Dietz's group 10 described the transperineal route as the most suitable since it induces less anatomical deformation and functional changes in pelvic organs, and also is less uncomfortable for the patient, but the probe used was abdominal because, in our opinion, it allows better visualization of the three compartments. We used a transvaginal probe for the threedimensional study, since it provides a wide enough angle of insonation, facilitates visualizing the three compartments in a single image, and is much more manageable due to its smaller size; it can readily be held still during the capture of volumes. In our study, we captured one volume to assess the central and anterior compartments and another for the posterior compartment because we believe visualization of the posterior wall of the rectal ampulla, which is necessary to measure the ARA, is more accurate when the volume is captured independently. For the assessment of ultrasound variables, most studies recommend an intermediate bladder volume, avoiding extremes, and this was followed in the present study despite the fact that some studies have shown that ultrasound variables are not affected by bladder filling volume. ${ }^{[10,11]}$ In addition, following the recommendations of Dietz, ${ }^{[10]}$ it is preferable that the rectal ampulla be empty for more accurate measurements.

In most published studies, only two examinations were performed, one before and one after delivery, and changes occurring throughout pregnancy, as in the present work, were not recorded. Tunn et al. ${ }^{[12]}$ showed that immediately after birth there is a functional deficit of the pelvic floor muscles, followed by a partial spontaneous recovery about six months after delivery. Our last examination was performed at three months postpartum, which we regard as sufficient time to see some recovery of the pelvic floor, in order to minimize loss of patients to follow-up. In fact, our data show significant changes in most variables between the fourth and the fifth visit, confirming that recovery at three months is already evident.

With regard to measurement of the ultrasound variables considered in the present study, several published studies have reported using the same methodology to measure the posterior UVA, LHA and ARA. ${ }^{[13]}$ However, for urethral sphincter volume (USV), periurethral vascularization and the maximum height of the AWA, we found no references in the literature since they are described here for the first time.

In assessing USV, both in vitro and in vivo studies have demonstrated the high accuracy of 3D-US in estimating volume using the pre-set rotational planes of the VOCAL technique. ${ }^{[14]}$ In addition, the reliability of three-dimensional ultrasound has proved superior to two-dimensional ultrasound. ${ }^{[15]}$ Robinson et al. ${ }^{[16]}$ calculated the volume of the urethral sphincter by 3D-US, but the study was conducted with transvaginal ultrasound in the early 90s, and 3D-US has advanced greatly since then. Digesu et al. ${ }^{[17]}$ recently published a method of measuring the urethral sphincter using a 3D vaginal probe via the transperineal route, with an ultrasound scanner similar to ours. They measured the sphincter in the axial plane, manually tracing the area of the outer edge first, the then that of the interior edge, in both cases measuring multiple planes $1 \mathrm{~mm}$ apart to complete the entire length of the sphincter. The difference with respect to our study is that they did not use the VOCAL rotational method, which we believe simplifies the operation and requires less time to calculate the volume, as well as offering increased accuracy thanks to the preset rotational planes.

With respect to periurethral vascularization, the exact relationship between the various 3D indices with actual blood flow is not fully known, and research on this is still ongoing. However, it seems that these indices have demonstrated their reliability to assess vascularization; various studies have reported reproducible 3D results on blood flow in complex networks, such as the endometrium and the ovary, with very high intra-class and correlation coefficients. ${ }^{[17,18]}$

There are publications on female periurethral vascularization, but most are 2D-US studies. ${ }^{[19]}$ Liang et al. ${ }^{[20]}$ published their results on periurethral vascularity with 3D-PDA using color histograms and the three vascular indices IV, IF and IVF. However, the big difference is that they applied a threshold of $5 \mathrm{~mm}$ for the periurethral area instead of the $3 \mathrm{~mm}$ we used in our study. Considering the anatomical distribution of urethral vascularity shown in Doppler flow maps, it appears that beyond $3 \mathrm{~mm}$ one begins to include vessels of the vaginal wall and the results may thus be contaminated. 
Regarding the study of AWA, many authors have described images of paravaginal defects observed in the axial plane of the urogenital hiatus, ${ }^{[21,22]}$ but these studies have focused only on describing the shape of the anchors, so their correlation with the clinical examination of patients was questionable and reproducibility was poor. ${ }^{[22]}$ In addition, we here present a new anthropometric parameter, the AWA, that is not a subjective impression of these anchors, but a measure of the maximum height they present before and after childbirth. The TUI (Tomographic Ultrasound Imaging) mode with multiple slices only $1 \mathrm{~mm}$ apart allows precise measurement of these anchors (see Figure 2B).

\subsection{On the results}

The proportion of patients who developed urinary loss during pregnancy decreased after delivery, as reported by other authors. ${ }^{[23]}$

We observed a significant increase in UVA during pregnancy, which coincides with the results of Wijma et al., ${ }^{[23]}$ but they did not continue their study after delivery. Costantini et al. ${ }^{[24]}$ reported UVA measurements before and after birth with similar results to ours, but their study only included three examinations, one before 36 weeks and two after delivery - at one week and three months postpartum, without evaluating changes occurring during pregnancy.

We observed that UVA differences between the first and the fifth visit were greater in patients who received epidural analgesia during labor. However, we were unable to compare these results with those of other authors for the lack of data from similar studies. Furthermore, in patients reporting urine loss at three months postpartum, there was no recovery of UVA as in the rest of the patients, which indicates a relationship between this variable and continued urine loss.

The significant decrease observed in USV during pregnancy and after delivery is comparable to that reported by Robinson et al. ${ }^{[16]}$ They found that USV before delivery was 1.15 $\mathrm{cm}^{3}$ versus $1.01 \mathrm{~cm}^{3}$ after delivery, which are somewhat lower than those found in the present study $\left(1.74 \mathrm{~cm}^{3}\right.$ at 36 weeks and $1.49 \mathrm{~cm}^{3}$ at three months postpartum. These discrepancies could be related to the different methods used, and secondly to the differences in time periods (weeks of pregnancy) in which the examinations were performed, and the long interval described by Robinson is sufficient to explain the discrepancies. Even so, the loss of USV described by Robinson before and after delivery is similar to that observed in our study $\left(0.14 \mathrm{~cm}^{3}\right.$ in Robinson's study, compared to $0.25 \mathrm{~cm}^{3}$ in our study).

We observed major differences in loss of USV according to the type of delivery (greatest loss in instrumental deliveries, followed by spontaneous and then caesarean deliveries). Interestingly, the patients with urinary frequency showed greater loss of USV at three months postpartum, indicating a possible relationship between USV and voiding function.
Periurethral vascularization increased throughout pregnancy and decreased after birth. This coincides with the data provided by Liang et al. ${ }^{[20]}$ showing higher periurethral vascularity in pre-menopausal patients than in menopausal patients due to their hormonal status. The three vascular indices were consistent with our results, although curiously we found no correlation with USV.

The best vascular indices were found in patients who received oxytocin during labor, perhaps due to the vasoconstrictor effect of this hormone. Moreover, in our case, VI and VFI correlated with the mode of delivery, with better postpartum vascularization in patients with lower obstetric trauma (higher vascularization in women with cesarean deliveries versus spontaneous deliveries and the least in instrumented deliveries).

For female pelvic floor assessment, the parameter most extensively studied using 3D-US is probably LHA. Its dimensions and distension vary between populations of women, as reflected by the great variability in hiatal area size published to date. ${ }^{[13,16,24]}$ Our measures of LHA, made in primiparous women during the first trimester of gestation (mean $11.71 \mathrm{~cm}^{2}$ ) coincide with those of other authors $\left(10.5 \mathrm{~cm}^{2}\right) .{ }^{[25]}$ In our sample, LHA increased progressively throughout pregnancy and then decreased after childbirth, but not to its original size in the first trimester. Svabik et $a l .{ }^{[4]}$ described a mean LHA at week 36 in nulliparous pregnant women of $14.13 \mathrm{~cm}^{2}$ in repose and $20.17 \mathrm{~cm}^{2}$ with Valsalva maneuver, somewhat larger than in our patients $\left(12.53 \mathrm{~cm}^{2}\right.$ in repose and $13.39 \mathrm{~cm}^{2}$ with Valsalva maneuver at week 36). Shek and Dietz ${ }^{[26]}$ found a decrease in mean LHA of $0.54 \mathrm{~cm}^{2}$ between week 36 of pregnancy and three months postpartum. In our study, mean LHA also decreased at three months postpartum compared to the fourth visit, but between the third and the fifth visit, LHA remained virtually unchanged.

It is relevant to note that at three months of delivery, LHA was highest in women who had instrumented deliveries compared to spontaneous deliveries, and lowest in those with cesarean deliveries. Patients who received oxytocin and epidural during labor had lower LHA and better hiatal recovery at three months of delivery. We suspect that epidural analgesia probably has a muscle relaxant effect on the perineum, thus promoting hiatal distension. On the contrary, we observed that the longer the expulsion period and the greater the fetal head circumference, the greater the LHA at three months postpartum. These variables have also been studied by other authors, ${ }^{[7,8]}$ although not related to the dimensions of LHA but to the presence of lesions.

The maximum height of the AWA which we anthropometrically quantified for the first time has provided interesting results in our study. Our results are significant and important in the study of the changes taking place in the pelvic floor during pregnancy and the postpartum. 
Finally, regarding the ARA, despite the large number of studies on the subject, most were performed radiologically, and ARA data in pregnant women are not described. In general, most studies involving 3D-US are limited to assessing and describing anal sphincter injury following childbirth. Santoro ${ }^{[27]}$ and Huang ${ }^{[28]}$ described mean values of ARA in non-pregnant nulliparous women, so we can only compare our results from the first trimester of pregnancy with theirs; in fact these measurements are comparable $\left(133.5^{\circ}\right.$ and $125^{\circ}$ versus $131.5^{\circ}$ in our study). In our experience, ARA increased during pregnancy and decreased in the postpartum period. Regarding the mode of delivery, mean ARA was significantly higher in women with vaginal versus cesarean deliveries.

\section{Conclusions}

The 3D-PDA technique (VI, FI, and VFI) is most useful for the assessment of periurethral vascularization. AWA height as a new anthropometric parameter should be included as another numeric indicator in the study of the pelvic floor. In addition, since pelvic floor physiology and anatomy in general, and maybe this parameter in particular, are influenced by parity, further multicentric studies also including multiparous patients are needed to improve and increase the knowledge on this topic.

The VOCAL method with automatic threshold mode (MVM) proved reliable and the least time-consuming way to measure urethral sphincter volume.

\section{References}

[1] Liu J, Guaderrama N, Nager CW, et al. Functional correlates of anal canal anatomy: puborectalis muscle and anal canal pressure. Am J Gastroenterol. 2006; 101: 1092-7. PMid: 16606349. http: $/ / \mathrm{dx}$.doi.org/10.1111/j.1572-0241.2006.00596.x

[2] Milsom I, Ekelund P, Molander U, et al. The influence of age, parity, oral contraception, hysterectomy and menopause on the prevalence of urinary incontinence in women. J Urol. 1993; 149: 1459-62. PMid: 8501788

[3] Dietz HP. Quantification of major morphological abnormalities of the levator ani. Ultrasound Obstet Gynecol. 2007; 29: 329-34. PMid: 17323308. http://dx.doi.org/10.1002/uog. 3951

[4] Svabík K, Shek KL, Dietz HP. How much does the levator hiatus have to stretch during childbirth? BJOG. 2009; 116: 1657 62. PMid: 19735376. http://dx.doi.org/10.1111/j.1471-0 528.2009.02321. $\mathrm{x}$

[5] Shek KL, Dietz HP. The effect of childbirth on hiatal dimensions. Obstet Gynecol. 2009; 113: 1272-8. PMid: 19461422. http://dx .doi.org/10.1097/AOG.0b013e3181a5ef23

[6] Alouini S, Rossard L, Lemaire B, et al. Anal sphincter tears after vaginal delivery: risks factors and means of prevention. Rev Med Liege. 2011; 66: 545-9. PMid: 22141262.

[7] Krofta L, Otcenásek M, Kasíková E, et al. Pubococcygeuspuborectalis trauma after forceps delivery: evaluation of the levator ani muscle with 3D/4D ultrasound. Int Urogynecol J Pelvic Floor Dysfunct. 2009; 20: 1175-81. PMid: 19639235. http://dx.doi . org/10.1007/s00192-009-0837-6

[8] Dandolu V, Chatwani A, Harmanli O, et al. Risk factors for obstetrical anal sphincter lacerations. Int Urogynecol J Pelvic Floor Dysfunct. 2005; 16: 304-7. PMid: 15809773. http://dx.doi.org/1 $0.1007 / \mathrm{s} 00192-005-1297-2$

[9] Timmermans L, Falez F, Mélot C, et al. Validation of use of the International Consultation on Incontinence Questionnaire-Urinary Incontinence-Short Form (ICIQ-UI-SF) for impairment rating: a transversal retrospective study of 120 patients. Neurourol Urodyn. 2013; 32: 974-9. PMid: 23281067. http://dx.doi.org/10.10 02/nau. 22363

[10] Dietz H. Pelvic floor ultrasound: Basic physics, instrumentation and examination technique. In: Dietz HP, Hoyte L, Steensma A, eds. Atlas of pelvic floor ultrasound. London: Springer; 2008. http://dx.doi.org/10.1007/978-1-84628-584-4_2

[11] Mouritsen L, Bach P. Ultrasonic evaluation of bladder neck position and mobility: the influence of urethral catheter, bladder volume, and body position. Neurourol Urodyn. 1994; 13: 637-46. PMid: 7697055. http://dx.doi.org/10.1002/nau.1930130603
[12] Tunn R, Schaer G, Peschers U, et al. Updated recommendations on ultrasonography in urogynecology. Int Urogynecol J Pelvic Floor Dysfunct. 2005; 16: 236-41. PMid: 15875241. http://dx.doi.o $\mathrm{rg} / 10.1007 / \mathrm{s} 00192-004-1228-7$

[13] Dietz HP, Shek C, Clarke B. Biometry of the pubovisceral muscle and levator hiatus by three-dimensional pelvic floor ultrasound. Ultrasound Obstet Gynecol. 2005; 25: 580-5. PMid: 15883982. http://dx.doi.org/10.1002/uog.1899

[14] Farrell T, Leslie JR, Chien PF, et al. The reliability and validity of three dimensional ultrasound volumetric measurements using an in vitro balloon and in vivo uterine model. BJOG. 2001; 108: 57382. PMid: 11426890 . http://dx.doi.org/10.1111/j.1471-0 $528.2001 .00148 \cdot x$

[15] Yaman C, Jesacher K, Pölz W. Accuracy of three-dimensional transvaginal ultrasound in uterus volume measurements; comparison with two-dimensional ultrasound. Ultrasound Med Biol. 2003; 29: 1681-4. http://dx.doi.org/10.1016/S0301-5629(03)0 1070-6

[16] Robinson D, Toozs-Hobson P, Cardozo L, et al. Correlating structure and function: three-dimensional ultrasound of the urethral sphincter. Ultrasound Obstet Gynecol. 2004; 23: 272-6. PMid: 15027017. http://dx.doi.org/10.1002/uog. 987

[17] Digesu GA, Calandrini N, Derpapas A, et al. Intraobserver and interobserver reliability of the three-dimensional ultrasound imaging of female urethral sphincter using a translabial technique. Int Urogynecol J. 2012; 23: 1063-8. PMid: 22270730. http://dx.doi.o $\mathrm{rg} / 10.1007 / \mathrm{s} 00192-012-1669-3$

[18] Mercé LT, Alcázar JL, Engels V, et al. Endometrial volume and vascularity measurements by transvaginal three-dimensional ultrasonography and power Doppler angiography in stimulated and tumoral endometria: intraobserver reproducibility. Gynecol Oncol. 2006; 100: 544-50. PMid: 16243383. http://dx.doi.org/10. $1016 / j \cdot$ ygyno .2005 .09 .024

[19] Wieczorek AP, Woźniak MM, Stankiewicz A, et al. Quantitative assessment of urethral vascularity in nulliparous females using highfrequency endovaginal ultrasonography. World J Urol. 2011; 29: 625-32. PMid: 21796481. http://dx.doi.org/10.1007/s0034 5-011-0732-x

[20] Liang CC, Chang SD, Chang YL, et al. Three-dimensional power Doppler measurement of perfusion of the periurethral tissue in incontinent women - a preliminary report. Acta Obstet Gynecol Scand. 2006; 85: 608-13. PMid: 16752242. http://dx.doi.org /10.1080/00016340500342920

[21] Dietz HP, Steensma AB, Hastings R. Three-dimensional ultrasound imaging of the pelvic floor: the effect of parturition on paravaginal support structures. Ultrasound Obstet Gynecol. 2003; 21: 589-95. PMid: 12808677. http://dx.doi.org/10.1002/uog. 100 
[22] Dietz HP, Pang S, Korda A, et al. Paravaginal defects: a comparison of clinical examination and 2D/3D ultrasound imaging. Aust N Z J Obstet Gynaecol. 2005; 45: 187-90. PMid: 15904441. http://dx.doi.org/10.1111/j.1479-828X.2005.00377.x

[23] Wijma J, Weis Potters AE, de Wolf BT, et al. Anatomical and functional changes in the lower urinary tract during pregnancy. BJOG. 2001; 108: 726-32. PMid: 11467699. http://dx.doi.org/10. 1111/j.1471-0528.2001.00123.x

[24] Costantini S, Esposito F, Nadalini C, et al. Ultrasound imaging of the female perineum: the effect of vaginal delivery on pelvic floor dynamics. Ultrasound Obstet Gynecol. 2006; 27: 183-7. PMid: 16388512. http://dx.doi.org/10.1002/uog. 2663

[25] Duckett J, Lautmann K. Ultrasound changes in the relationship between the urethra and bladder neck caused by prolapse repair: feasibility and reliability of measurements. J Obstet Gynaecol. 2012;
32: 672-5. PMid: 22943715.http://dx.doi.org/10.3109/014 43615.2012.711390

[26] Shek KL, Dietz HP. Intrapartum risk factors for levator trauma. BJOG. 2010; 117: 1485-92. PMid: 20735379. http://dx.doi.o $\mathrm{rg} / 10.1111 / \mathrm{j} .1471-0528.2010 .02704 . \mathrm{x}$

[27] Santoro GA, Wieczorek AP, Shobeiri SA, et al. Interobserver and interdisciplinary reproducibility of $3 \mathrm{D}$ endovaginal ultrasound assessment of pelvic floor anatomy. Int Urogynecol J. 2011; 22: 539. PMid: 20700728. http://dx.doi.org/10.1007/s00192-0 10-1233-y

[28] Huang WC, Yang SH, Yang JM. Three-dimensional transperineal sonographic characteristics of the anal sphincter complex in nulliparous women. Ultrasound Obstet Gynecol. 2007; 30: 210-20. PMid: 17659660. http://dx.doi.org/10.1002/uog. 4083 